\title{
Effect of Low Level Ozone Exposure on the Serum TBA-Reactive Substance (TBA-RS) Level and Gill Superoxide Dismutase and Catalase Activities in Rainbow Trout
}

\author{
Jun Morita, ${ }^{* 1}$ Tetsuya Suzuki, ${ }^{* 1}$ Shizuo Kimura, ${ }^{* 2}$ \\ Akihiko Hara, ${ }^{* 2}$ and Kozo Takama*1, ${ }^{*}$ \\ ${ }^{* 1}$ Laboratory of Food Hygiene, Department of Food Science and Technology, Faculty of Fisheries, \\ Hokkaido University, Minato, Hakodate 041, Japan \\ ${ }^{*}$ Nanae Experimental Aquaculture Station, Faculty of Fisheries, Hokkaido University, \\ Nanae 041-11, Japan
}

(Received July 5, 1994)

Key words: ozone exposure, rainbow trout, superoxide dismutase, catalase, serum TBA-RS

Ozone has recently been used for sterilization of water in aquaculture. However, enough care should be taken in its utilization for aquaculture because of its potent toxicity to organisms. Many papers on the toxicity of ozone to fishes have been reported. ${ }^{1-4)}$ For practical use, ozone is generally used in the hatcheries at ppb level discontinuously. ${ }^{1)}$ However, acute or subacute toxicity of low level ozone exposure to fishes from the standpoint of reactive oxygen and its scavenging system has remained unknown. We previously reported that brief ozone exposure at ppm level definitely causes fatal damage to fresh water fishes. ${ }^{5-8)}$ In our previous studies, it was suggested that imbalance of activities of SOD and catalase seems to be important in showing reactive oxygen damage. ${ }^{8)}$

We report here preliminarily on how consecutive $p p b$ level ozone exposure affects serum malondialdehyde (MDA) level and activities of gill SOD and catalase of rainbow trout. Rainbow trout Onchorynchus mykiss (4 6 fish) $\left[1^{+}\right.$, body weight ranging from $62 \sim 113 \mathrm{~g}$, body length $17.3 \sim 21.3 \mathrm{~cm}$ ] used as a test fish species were exposed to ozone for 7 consecutive days by feeding water containing $20 \mathrm{ppb}$ ozone into an aquaculture tank kept at $7^{\circ} \mathrm{C}$. Exposure was run for 5 hours each day. Ozone was generated by electrolysis type ozone generator, Pure Zone (type S-600; Permereck Electrode Co. Ltd., Fujisawa, Japan). Concentration of ozone generated at ppm level was monitored by iodometry, ${ }^{9)}$ and then diluted to $20 \mathrm{ppb}$ by mixing with well water. Four to six rainbow trout for each period of ozone exposure were used to assay serum TBA-RS level ${ }^{8)}$ and activities of gill SOD and catalase after exposure for $0,2,4$, and 7 days. Blood collection and isolation of gills, done immediately after finishing ozone exposure for required period were kept at $-70^{\circ} \mathrm{C}$ until determination of TBA-RS level and enzyme assay. During the ozone exposure experiment, rainbow trout were kept in an intensive aquaculture apparatus described in the previous paper $^{6)}$ and were not fed at all.

Assay of SOD (EC1.15.1.1) and catalase (EC1.11.1.6) and determination of serum TBA-RS levels were carried out according to the methods described in the previous papers. ${ }^{8)}$

On comparing serum TBA-RS levels of ozone exposed fish with those of the control fish, it was found that there were no significant differences except those from 4 days ozone exposure (Fig. 1). Figure 2 shows activities of SOD and catalase in the gills with or without ozone exposure. While the catalase activity did not change throughout the experiment, SOD activities decreased with time. Activities of SOD of the control fish were higher than those of ozone exposed fish at 2 and 4 days, however, no significant difference was observed for the fish that were run for 0 and 7

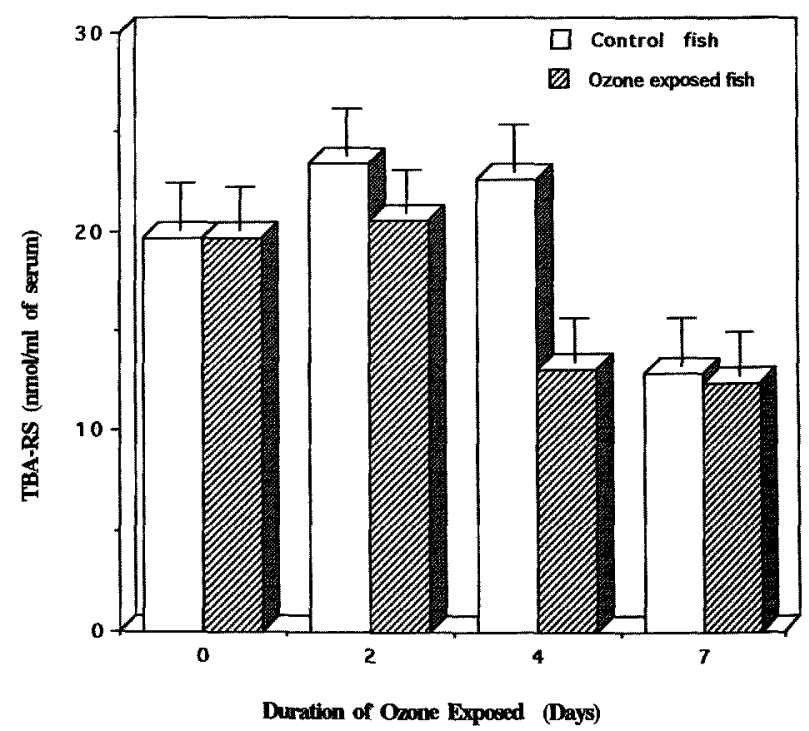

Fig. 1. Serum TBA-RS Levels of Control and Ozone Exposed Rainbow Trout.

Data representing TBA-RS levels are expressed as nmol of TBARS per $\mathrm{ml}$ of serum from 5 fish. Bar indicates standard error of means. Fish were exposed $20 \mathrm{ppb}$ ozone for 5 hours everyday for consecutive 7 days. Other experimental details are in the text.

\footnotetext{
$\uparrow$ To whom all the correspondence should be addressed.
} 


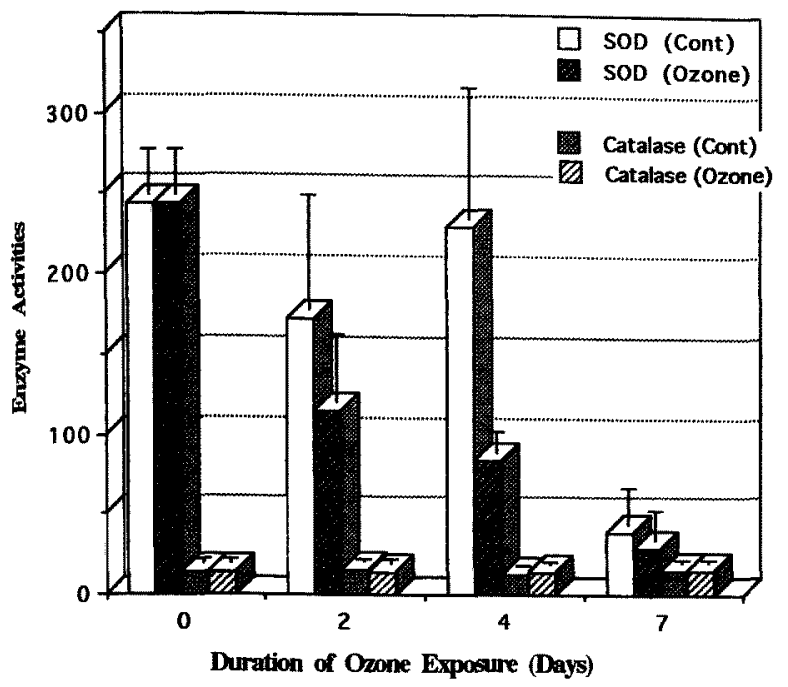

Fig. 2. Activities of Gill SOD and Catalase of Control and Ozone Exposed Rainbow Trout.

SOD activity is expressed as unit per mg protein, and catalase activity is expressed as decomposed $\mathrm{H}_{2} \mathrm{O}_{2} \mathrm{mmol} / \mathrm{min} / \mathrm{mg}$ protein. Data were obtained from 6 fish. Error bars for SOD indicate standard deviation. (Cont) and (Ozone) mean control fish group and ozone exposed fish group, respectively.

days exposure. Decrease of serum TBA-RS level and SOD activities of both control and ozone exposed fish after 7 days remains unclear, however, they may be due to the effect of starvation. The fact that SOD activity and serum TBA-RS level of 4 days ozone exposure were the lowest may suggest an important implication in the relation of reactive oxygen scavenging enzyme activities and its reflection on serum TBA-RS level. Although this is just our hypothesis, low level of serum TBA-RS after 4 days could be due to suppression of SOD activity so that excessive generation of hydrogen peroxide from ozone through superoxide is held back. Another assumption is that the amount of polyunsaturated fatty acid is reduced to adapt to an oxidative environment during ozone exposure. Experimental verification is needed before any conclusions can be drawn about the study's implication for the relationship between suppression of SOD and serum TBA-RS under the low level ozone exposure. The present preliminary study suggests that continual low concentration ozone exposure at ppb level does not cause any impairment to rainbow trout.

The authors are indebted to Japan Medix Co. Ltd. for its kind supply of ozone generator and to Dr. K. Fukunaga for his technical assistance and advice. Thanks are due to Mr. Christian O. Nyako, Laboratory of Marine Zoology, Faculty of Fisheries, Hokkaido University for his kind manuscript reading and suggestions.

\section{References}

1) P. J. Colberg and A. J. Lingg: J. Fish. Res. Board Can., 35, 12901296 (1978).

2) G. A. Wedemeyer, C. Nelson Nancy, and T. Yasutake William: $J$. Fish. Res, Board Can., 36, 605-614 (1979).

3) M. H. Paller: Environ. Pollut. (Ser. A), 22, 229-239 (1988).

4) J. M. Tipping: The Progressive Fish-Culturist, 50, 202-210 (1988).

5) K. Fukunaga, T. Suzuki, and K. Takama: Comp. Biochem. Physiol., 100B, 481-487 (1991).

6) K. Fukunaga, T. Suzuki, M. Arita, S. Suzuki, A. Hara, K. Yamauchi, N. Shinriki, K. Ishizaki, and K. Takama: Comp. Biochem. Physiol., 101C, 331-336 (1992).

7) K. Fukunaga, T. Suzuki, A. Hara, and K. Takama: Nippon Suisan Gakkaishi, 58, 171 (1992).

8) K. Fukunaga, T. Suzuki, A. Hara, and K. Takama: Free Radical Research Commun., 17, 327-333 (1992).

9) H. Schachter: Water Res., 7, 729-739 (1973). 